\title{
Consumption pattern of environment and skin friendly cleansing agents for ceramic tile surfaces
}

See end of the paper for authors' affiliations Ritika Dixit

Department of Family Resource Management, Punjab Agricultural University, Ludhiana (Punjab) India
ABSTRACT : The present study was conducted to know the consumption pattern of cleansing agents among respondents and problems experienced while using these. The present study was conducted in two phase's i.e. household survey and laboratory experiments. In first phase a sample of sixty respondents from two localities of Ludhiana city, selected by using simple random sampling technique, was surveyed by personal interview using structured interview schedule. The results of the survey revealed that commercial liquid cleansing agents were found to be the most popularly used cleansing agents for household cleaning. The average quantity of commercial liquid cleansers being used was $1.761 /$ month and average monthly expenditure on these cleaners was Rs. 102. Floor tiles and toilet bowls were washed daily by more that 50 per cent of respondents. As high as 80 per cent of respondents faced the problem of dryness of skin by using detergent powder, around 22.0 per cent respondents reported breathing problems by using commercial liquid cleansing agents.

KEY WORDS: Cleansing agents, Consumption, Cleansing efficiency

HOW TO CITE THIS PAPER : Dixit, Ritika and Kaur, Surinderjit (2018). Consumption pattern of environment and skin friendly cleansing agents for ceramic tile surfaces. Asian J. Home Sci., 13 (1) : 221224, DOI: 10.15740/HAS/AJHS/13.1/221-224. Copyright@ 2018: Hind Agri-Horticultural Society. 